\title{
Different milk feeding intensities during the first 4 weeks of rearing in dairy calves: Part 1: Effects on performance and production from birth over the first lactation
}

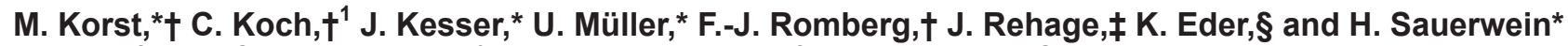 \\ ${ }^{*}$ Institute of Animal Science, Physiology \& Hygiene Unit, University of Bonn, Bonn 53115, Germany \\ †Educational and Research Centre for Animal Husbandry, Hofgut Neumuehle, Muenchweiler a.d. Alsenz 67728, Germany \\ ¥University of Veterinary Medicine, Foundation, Hannover 30559, Germany \\ §Institute of Animal Nutrition and Nutritional Physiology, Justus-Liebig University, Giessen 35392, Germany
}

\begin{abstract}
We aimed to test the effects of ad libitum feeding of whole milk (WM) or milk replacer (MR) versus restrictive feeding of MR during the first 4 wk of life on growth performance and on milk yield in the first lactation. We studied 57 German Holstein calves (29 females, 28 males) from birth until d 110 of life (trial 1). The 28 females from trial 1 were further studied during their first lactation (trial 2). In trial 1, all calves were randomly allocated at birth to 1 of 3 groups: MRres $[\mathrm{n}=20,6.78 \mathrm{~kg} \mathrm{MR}(11.5 \%$ solids $) /$ calf per day], MR-ad lib ( $\mathrm{n}=17,13.8 \%$ solids) or WM-ad lib ( $\mathrm{n}=$ 20). All calves received colostrum ad libitum from their dam until d 3 of age. From d 4 to 27, calves were fed according to their group regimen. From d 28 to 55, all calves received MR-res feeding and were then gradually weaned until d 69. We recorded body weight (until d 110) and feed intake (amount, metabolizable energy, and frequency of liquid feed intake until weaning). We estimated the profitability of the different feeding regimens, taking into account income from milk yield (trial 2 ) and feed costs during rearing. In trial 1 , the calves from WM-ad lib and MR-ad lib had total metabolizable energy intakes 2.02- and 1.65-fold greater than the MR-res group during the first 4 wk of life. During this period, concentrate intake did not differ among groups, but tended to be greater in WM-ad lib than in MR-ad lib calves from d 28 to 69 . The MR-res calves visited the automatic feeders more often than the ad libitumfed groups during differential feeding, but $70 \%$ of the visits were unrewarded $(<10 \%$ in the ad libitum-fed calves). When all calves were fed at the MR-res level, the average proportion of unrewarded visits was $65 \%$ in all groups. Average daily gain and body weight were greater among MR-ad lib and WM-ad lib calves than
\end{abstract}

Received June 12, 2016.

Accepted December 1, 2016.

${ }^{1}$ Corresponding author: c.koch@neumuehle.bv-pfalz.de among MR-res animals during the first 4 wk of life, but not from d 1 to 110 . In trial 2, age at first calving, dry matter intake, and body weight over the first 10 mo of lactation were not different among groups, nor was milk composition. Milk yields (305 d) were numerically but not statistically greater in the ad libitum-fed groups during the first lactation $(+765 \mathrm{~kg}$ for WM-ad lib vs. MR-res; $+612 \mathrm{~kg}$ for MR-ad lib vs. MR-res). Feeding WM-ad lib and MR-ad lib was 1.37- and 1.21-fold more costly than MR-res, respectively, but amounted to 18 , 15 , and $13 \%$ of the total estimated feed costs until first calving in WM-ad lib, MR-ad lib, and MR-res, respectively. Our study confirms that ad libitum feeding is an attractive measure for rearing dairy calves, both for animal welfare and - with the caveat of a small sample size in trial 2 that led to insufficient power-economic profit from milk.

Key words: calf, nutrition, growth, milk yield

\section{INTRODUCTION}

Calves are born without a functional rumen, and nutrients are provided mainly in liquid form - as whole milk (WM) or milk replacer (MR) during the first week of life (Baldwin et al., 2004; Khan et al., 2011). Over the past decades, feeding strategies for dairy calves have focused on early weaning to stimulate intake of solid feed and development of a functional forestomach system (Baldwin et al., 2004; Khan et al., 2011, 2012, 2016). Restricting liquid feed before weaning is meant to drive the intake of concentrate and the production of VFA (in particular butyrate), which are the primary drivers of rumen development (Quigley et al., 1991). However, restricting the amount of liquid feed results in lower growth rates, abnormal behavior, and negative effects on rumen development (Khan et al., 2011, 2016).

The effects of increasing nutrient supply with WM or MR on feed intake, growth rate, and milk yield in the first lactation have been investigated recently (Soberon et al., 2012; Eckert et al., 2015; Kiezebrink et 
al., 2015). Increasing WM or MR intake decreased concentrate intake (Khan et al., 2007a,b; Raeth-Knight et al., 2009), delayed rumen development, and decreased BW at weaning (Suarez-Mena et al., 2011). However, Robelin and Chilliard (1989) and Moallem et al. (2010) found that increased ADG during the first 2 mo of life resulted in greater BW at 24 mo of age. Higher growth rates in early life reportedly improve gastrointestinal development at weaning (Eckert et al., 2015), lower age at first calving (Raeth-Night et al., 2009), and increase first-lactation milk yield, although not always significantly (Margerison et al., 2013; Soberon and Van Amburgh, 2013).

Brown et al. (2005) documented that increasing the intake of energy and protein from 2 to $14 \mathrm{wk}$ of age affected the development of the mammary gland in heifer calves: that is, total parenchymal mass and parenchymal DNA and RNA increased, and histological development was stimulated. A recent report (Geiger et al., 2016) confirmed these results and documented that intensified feeding over 8 wk of life resulted in increased organ weights (e.g., liver, mammary gland, spleen).

The "lactocrine hypothesis" emanated from the notion that milk-borne factors may affect the development of specific tissues or physiological functions and exert long-term effects (Bartol et al., 2008, 2013). Such findings were first described in neonatal pigs (Donovan and Odle, 1994; Burrin et al., 1997) and subsequently also in calves (Blum and Hammon, 2000; Rauprich et al., 2000a,b; Blättler et al., 2001). Indeed, the results of these studies showed that neonates may undergo programming by early nutrition that has sustained longterm effects (e.g., on the gastrointestinal tract, liver, and mammary gland). Milk-borne factors are constituents of WM, occurring at particularly high concentrations in colostrum (Blum and Hammon, 2000), whereas MR contains few such bioactive substances. The potentially sustained effects of early intensive WM feeding might thus be due to these bioactive substances, but also to energy and protein intake.

We aimed to test the following hypotheses: (1) Feeding WM or MR ad libitum for the first 4 wk of life and continuing thereafter on a restrictive regimen with MR until weaning at $10 \mathrm{wk}$ of life will result in improved performance until d 110 of life, and thereafter during the onset and course of the first lactation; (2) calves fed ad libitum with WM will perform better in later life than calves fed MR ad libitum; and (3) the costs of the 4 wk ad libitum feeding will be balanced by the returns achieved with the lactating animals. The effects of the different feeding strategies on the metabolic and endocrine status from birth over the first lactation are described in a companion paper by Kesser et al. (2017).

\section{MATERIALS AND METHODS}

The animal experiments were performed in strict accordance with the German Law for the Protection of Animals and were approved by the relevant authority (Landesuntersuchungsamt Rheinland-Pfalz, Koblenz, Germany; G 11-20-026). Two trials, 1 with calves and 1 with heifers recruited from the initial calf trial, were conducted at the Educational and Research Centre for Animal Husbandry, Hofgut Neumuehle, Muenchweiler a.d. Alsenz, Germany.

\section{Trial 1}

Animals, Housing, Feeding, and Sampling. German Holstein calves (29 females and 28 males) were studied from April 2012 to January 2013 during their first $110 \mathrm{~d}$ of life. All calves were born spontaneously at term and received $10 \mathrm{~mL}$ of iron suspension per os (Sinta fer-o-bac, $115 \mathrm{mg}$ of $\mathrm{Fe}^{3+} / \mathrm{mL}$ and $108 \mathrm{mg}$ of dextran/mL; Sinta GmbH, Schwarzenborn, Germany). Colostrum milked from their respective dams was provided ad libitum within $2 \mathrm{~h}$ after birth in the calving pen next to their dam. Calves were randomly allocated directly after birth to 1 of 3 different feeding groups, but differential feeding was not started until d 4 of life (i.e., after the colostrum phase). From the second feeding time until d 3 of age, all calves received colostrum and transition milk, respectively, ad libitum from their dam. From d 4 to d 27 of age, calves were fed according to their group regimen: calves in the milk replacer restricted group (MR-res, $\mathrm{n}=20,10$ males and 10 females) received MR $\left(11.5 \%\right.$ solids; $42^{\circ} \mathrm{C}$ mixing temperature and $39^{\circ} \mathrm{C}$ drinking temperature) limited to $6.78 \mathrm{~kg}$ of liquid fed/d (i.e., $0.78 \mathrm{~kg}$ of $\mathrm{MR}$ powder/d); calves in the milk replacer ad libitum group (MR-ad lib, $\mathrm{n}=17,8$ males and 9 females) and the whole milk ad libitum group (WM-ad lib, $\mathrm{n}=20,10$ males and 10 females) had free access $24 \mathrm{~h} / \mathrm{d}$ to MR (13.8\% solids) or WM, respectively. The acidified MR (pH 4.7) was provided by Trouw Nutrition Deutschland GmbH (Burgheim, Germany; Table 1). The WM was saleable bulk tank milk from Hofgut Neumuehle (average $3.9 \%$ fat and $3.3 \%$ protein) and was acidified with $2 \mathrm{~mL}$ of acidifier per L of WM (Schaumacid; H. W. Schaumann GmbH, Pinneberg, Germany) to attain a $\mathrm{pH}$ of 4.6. The WM was supplemented with a mix of trace elements and vitamins $(1 \mathrm{~mL} / \mathrm{L}$ Milkivit QuickMix, Trouw Nutrition Deutschland $\mathrm{GmbH}$ ). Neither birth weight (presented in the results section) nor first colostrum intake ( $\mathrm{g}$, mean \pm SEM) were different among the groups: $(2,334 \pm 211$ for MR-res, $2,245 \pm$ 211 for MR-ad lib, and 2,349 \pm 237 for WM-ad lib, $P$ 
$=0.94)$. For the first $7 \mathrm{~d}$ of life, all calves were kept in individual straw-bedded hutches (Flixbox, Mayer Maschinenbaugesellschaft mbH, Tittmoning, Germany) and fed twice daily by a teat bucket. The MR-res group received $3.4 \mathrm{~kg}$ of liquid $\mathrm{MR}$ at each of the morning and evening feedings. Both ad libitum groups were offered $9 \mathrm{~kg}$ of WM or MR at each morning and evening feeding, and the buckets were accessible all day to achieve free access. Feed intakes were quantified by subtracting the leftover feed from the offered amounts. From d 8 to d 69 of age, calves were housed in straw-bedded group pens (3 adjacent pens in the same barn) with an automatic feeding system (Vario Kombi, FörsterTechnik GmbH, Engen, Germany) in which the liquid feeds were provided according to group regimen. The calves in the different groups were mixed in the pens, and differential feeding was achieved with transponder collars, through which the calves had access to their group-specific diet. All calves had free access to water, grass hay (first cut, not chopped), and concentrate. The latter was also offered via the automatic feeding system (Vario Kombi, Förster-Technik GmbH). To allow the calves to get used to feed intake from the automated supplier, newly incoming calves were assigned to a "baby pen." At approximately 3 wk of age, the calves were moved to the neighboring pen, in which they also had access to automated feeding for liquid and concentrate according to their group allocation. At the end of differential feeding, when all calves were fed according to the MR-res protocol, the calves were moved to the third pen, in which MR and concentrate were supplied by automated feeder until weaning. From d 25 to d 27 of age, the calves in the MR-ad lib and the WM-ad lib groups were gradually adapted (reducing the daily feed intake by $0.86 \mathrm{~kg}$ on average) to the MR-res feeding regimen (11.5\% solids, maximal daily allowance of 6.78 $\mathrm{kg}$ liquid feed), on which they continued until d 55. All calves were then stepped down to $2 \mathrm{~kg}$ of liquid feed on d 69 (i.e., reducing daily offers by $0.34 \mathrm{~kg}$ liquid feed or $39.1 \mathrm{~g}$ MR powder). From d 70 onwards, MR supply was entirely stopped and all calves had free access to a TMR (Table 1) for lactating dairy cows until the end of the trial at d 110. The calves were housed in group pens.

Table 1. Ingredients and nutrient composition (\% of DM unless otherwise noted) of milk replacer (MR), concentrate, and TMR for heifers and lactating cows (trials 1 and 2)

\begin{tabular}{|c|c|c|c|c|c|}
\hline \multirow[b]{2}{*}{ Item } & \multirow[b]{2}{*}{ MR } & \multirow[b]{2}{*}{ Concentrate } & \multicolumn{3}{|c|}{ TMR } \\
\hline & & & Heifer & Lactating $^{1}$ & Lactating $^{2}$ \\
\hline \multicolumn{6}{|l|}{ Ingredient } \\
\hline Grass silage & - & - & 85.8 & 20.1 & 23.0 \\
\hline Corn silage & - & - & - & 20.3 & 18.2 \\
\hline Pressed beet pulp silage & - & - & - & 19.4 & 12.8 \\
\hline Wheat straw and hay & - & - & 6.6 & 3.6 & 4.9 \\
\hline Barley & - & - & - & 9.1 & 10.6 \\
\hline Grain maize & - & - & - & 10.2 & 10.6 \\
\hline Solvent-extracted soybean meal & - & - & - & 3.4 & 5.7 \\
\hline Solvent-extracted rapeseed meal & - & - & 6.7 & 12.1 & 13.2 \\
\hline Vitamin and mineral mix & - & - & 0.9 & 1.5 & 0.8 \\
\hline Urea & - & - & - & 0.3 & 0.2 \\
\hline \multicolumn{6}{|l|}{ Nutrient composition } \\
\hline $\mathrm{DM}$ & 96.6 & 88.9 & 38.4 & 48.2 & 44.8 \\
\hline $\mathrm{CP}$ & 23.0 & 19.0 & 14.0 & 15.4 & 16.6 \\
\hline Crude fat & 17.0 & 4.1 & $\mathrm{ND}^{3}$ & ND & ND \\
\hline Crude fiber & 0.4 & 6.0 & 19.1 & 16.4 & 15.9 \\
\hline Crude ash & 7.4 & 7.4 & ND & ND & ND \\
\hline $\mathrm{ADF}_{\mathrm{OM}}^{4}(\%)$ & ND & $\mathrm{ND}$ & 31.8 & 31.5 & 19.7 \\
\hline $\operatorname{aNDF}_{\mathrm{OM}}{ }^{4}(\%)$ & ND & ND & 38.3 & 37.9 & 35.5 \\
\hline $\mathrm{NE}_{\mathrm{L}}^{5}(\mathrm{MJ} / \mathrm{kg} \mathrm{DM})$ & ND & ND & 5.8 & 6.8 & 7.0 \\
\hline $\mathrm{Ca}(\%)$ & 1.0 & 1.0 & $\mathrm{ND}$ & ND & ND \\
\hline $\mathrm{P}(\%)$ & 0.7 & 0.6 & ND & ND & ND \\
\hline $\mathrm{Na}(\%)$ & 0.4 & 0.3 & ND & ND & ND \\
\hline Lysine & 1.8 & ND & ND & ND & ND \\
\hline Methionine & 0.5 & ND & ND & ND & ND \\
\hline
\end{tabular}


All calves were subjected to repeated blood sampling from the jugular vein, from immediately after birth (d 0) until d 108 of age (total number of blood samples: 11). Liver biopsies were taken on d 19 and 100. In addition, glucose tolerance tests were performed in all calves on d 22, 52, and 108, and insulin tolerance tests were performed on d 24, 54, and 110 in the male calves only. Details of sampling, processing, storage, analysis, and results are described in the companion paper by Kesser et al. (2017).

Feed Intake. Daily MR and WM intake was documented individually from d 1 to 7 , when all calves were kept in individual hutches. From d 8 to 70 , $\mathrm{MR}$, WM, and concentrate intake was recorded daily per animal via the automatic feeding system (Vario Kombi, Förster-Technik GmbH). The contents of ME in MR and WM were calculated according to Jentsch et al. (2000); the ME content of the concentrate was analyzed according to the methods of the Verband der Deutschen Landwirtschaftlichen Untersuchungs- und Forschungsanstalten (VDLUFA, 2007). Daily ME intakes via MR, WM, and concentrate were calculated by multiplying the individual daily intake by the mean ME content (MJ/kg of DM) of MR (16.3), WM (19.3), and concentrate (11.6) for each calf, and are presented as average intake ( \pm SEM) per group from d 2 to 27 and d 28 to 69 . As well as the amounts consumed, the number of visits to the automatic feeders was recorded and classified as rewarded visits (feed was dispensed) and unrewarded visits (no feed when the daily allowance had been retrieved).

$\boldsymbol{B} \boldsymbol{W}$. All calves were weighed after the first colostrum feeding, and birth weight was determined by subtracting the amount of ingested colostrum. During trial 1, BW was recorded weekly from birth until d 110 using a mobile scale (Tru-Test Ltd., Auckland, New Zealand).

Economic Estimates. We calculated the total feed costs over the liquid feeding period from the average intake of MR, WM, or concentrate from d 4 until d 70 per group (MR-res, MR-ad lib, WM-ad lib), and the costs of the WM (€0.456/kg; i.e., €0.43 market price plus $€ 0.028 / \mathrm{kg}$ for the vitamin and mineral supplement used for WM), MR (€2.50/kg, respectively), and concentrate $(€ 0.38 / \mathrm{kg})$.

\section{Trial 2}

Animals, Housing, and Feeding. In 2014, the heifers from trial 1 ( $\mathrm{n}=28$; MR-res: $\mathrm{n}=10$, MR-ad lib: $\mathrm{n}=9$, WM-ad lib: $\mathrm{n}=9$ ) were allocated to a second trial. They were kept in straw-bedded group pens and had ad libitum access to a TMR for lactating dairy cows (Table 1) from d 70 until 7 mo of age. The heifers were then transferred to a loose-housing system with high boxes and rubber mattresses and were fed a TMR for heifers. The composition and nutrient content of the diets are provided in Table 1. Heifers were artificially inseminated when they had reached a minimum age of 15 mo and when spontaneous estrus was detected using activity sensors (leg-mounted Rescounter via Dairy Plan C 21; GEA Farm Technologies GmbH, Boenen, Germany) and visual observation. Three weeks before their expected calving date, heifers were integrated into the herd of lactating cows to become accustomed to the milking parlor (GEA Farm Technologies GmbH) and the weighing feed troughs (Insentec B. V., Marknesse, the Netherlands). During this time, they had free access to a TMR for lactating dairy cows (Table 1). The heifers were transferred to individual strawbedded calving pens 5 to $7 \mathrm{~d}$ antepartum. Immediately after calving, colostrum was milked from the heifer and fed directly to their calf next to them in the calving pen. The heifers were kept in group housing with straw bedding and ad libitum access to a TMR for lactating cows (Table 1) for the first $5 \mathrm{~d}$ postpartum. Thereafter, the heifers were transferred to group pens with strawbedded boxes along with the rest of the lactating herd, receiving the same TMR through the weighing troughs.

Collection of Samples and Data. During lactation, we recorded daily individual feed intake. The TMR was provided every morning $(0730 \mathrm{~h})$. All cows had free access to drinking water. Samples of all feedstuffs were collected every second week and stored at $-20^{\circ} \mathrm{C}$ until analysis. Feed samples were analyzed for crude ash, crude protein, crude fat, and crude fiber, as well as ADF content exclusive of residual ash and NDF content, assayed with a heat-stable amylase, exclusive of residual ash (VDLUFA, 2007). We calculated the $\mathrm{NE}_{\mathrm{L}}$ and crude protein content of the diets according to the German Society of Nutrition Physiology (GfE, 2001). Cows were milked twice daily at 0500 and 1530 h. Daily milk yield was recorded electronically via the herd management system Dairy Plan C21 (GEA Farm Technologies $\mathrm{GmbH}$ ), and milk samples were collected monthly over the first lactation (305 DIM) as combined aliquots from the evening and the next morning milking. Samples were stabilized with Bronopol (2-bromo2-nitropropane-1,3-diol, Sigma-Aldrich, Taufkirchen, Germany) and transported to the regional laboratory of the milk recording organization (Landeskontrollverband Rheinland-Pfalz-Saar e. V., Bad Kreuznach, Germany), where milk fat, protein, lactose, and SCC were analyzed via infrared analyzer (MilkoScan FT6000; Foss Analytical A/S, Hillerød, Denmark). Energy corrected milk (ECM) was calculated according to the equation provided by GfE (2001), which is adjusted to $4 \%$ fat and $3.4 \%$ protein. Energy balance was calculated individually from $\mathrm{NE}_{\mathrm{L}}$ intake per day minus 
the daily energy requirement for maintenance $\left(\mathrm{BW}^{0.75}\right.$ $\times 0.293$ ) and the daily energy output via ECM (GfE, 2001). Blood samples were taken monthly (3, 2, and 1 mo) antepartum and weekly (0 to $10 \mathrm{wk}$ ) postpartum from the jugular vein. Details and results of the blood analyses are reported in the companion paper by Kesser et al. (2017).

BW, Body Condition, and Back Fat Thickness. Body weight was recorded every second month from d 111 until calving with a mobile scale (Tru-Test Ltd.). After calving, BW was recorded twice daily after milking via an automatic scale (GEA Farm Technologies $\mathrm{GmbH}$ ). Back fat thickness was assessed by ultrasonography (Aloka SSD 500, $48 \mathrm{~mm}$, UST 5820, $5 \mathrm{MHz}$; Aloka GmbH, Meerbusch, Germany) as described by Schröder and Staufenbiel (2006). Body condition was scored every second week (BCS, 5 point scale; Edmonson et al., 1989).

Economic Estimates. We calculated the total feed costs from d 1 to 70 of life for all groups (MR-res, MR-ad lib, WM-ad lib) as described for trial 1. From d 70 until first calving, we used daily feed costs of €1.27. This number corresponds to the average from practical farms in Rhineland-Palatinate, Germany, at that time, as assessed by the extension services and authorized by the Ministry for Environment, Agriculture, Nutrition, Viticulture and Forestry in Rhineland-Palatinate (BZA-Rind, 2013). We calculated total feed costs from birth to first calving by summing the respective costs from $\mathrm{d} 1$ to 70 and the period until calving. To calculate the returns from milk, we used the average milk price in 2014, which was realized by Hofgut Neumuehle (€0.43/kg milk; Hochwald Foods GmbH, Thalfang, Germany), multiplied by the 305-d lactation milk yield per heifer. Milk returns over feed costs were calculated accordingly.

\section{Statistical Analyses}

We evaluated the sample size for both trials using BW gain and milk yield as target variables for trial 1 and trial 2, respectively. For trial 1, we used an ADG of $550 \mathrm{~g}$ during the first $27 \mathrm{~d}$ of life (i.e., until the end of differential feeding) with $10 \%$ variation for the MR-res fed group (the standard feeding on the experimental farm), and we assumed a 20\% increase (660 g) for ad libitum feeding. The sample size required $(\alpha=$ 0.05 , power $=0.8$ ) was $\mathrm{n}=5$ per group; trial 1 had a sample of 20 (10 of each sex) and so was well above the minimum requirement. For trial 2, which enrolled the female calves from trial 1 , the sample size was limited: assuming a theoretical 15\% increase in yield triggered by the ad libitum feeding, we would have needed $\mathrm{n}=$
14 per group for $80 \%$ power. We had $n=10$ per group, so power came down to $65 \%$.

We conducted all statistical analyses using SPSS (version 22.0; SPSS Inc., Chicago, IL). For statistical evaluation, trial 1 was divided in 4 phases $(\mathbf{P})$ : $\mathrm{P} 0=$ d 0 to $1, \mathrm{P} 1=\mathrm{d} 2$ to $27, \mathrm{P} 2=\mathrm{d} 28$ to 69 and $\mathrm{P} 3=\mathrm{d}$ 70 to 110 . At the end of each phase, we tested the differences in performance data among the feeding groups MR-res $(\mathrm{n}=20)$, MR-ad lib $(\mathrm{n}=17)$, and WM-ad lib $(\mathrm{n}=20)$ by ANOVA. We checked the homogeneity of variance using the Levene's test $(P>0.10)$ and, in cases of significance, we used the Kruskal-Wallis test for nonparametric tests. We analyzed the data for ADG and feed intake during the calves' first weeks of life (trial 1) using linear mixed models: group, sex, phase, and the interaction of group $\times$ phase were included as fixed effects and calf as random effect. The performance data of the heifers (trial 2) were also tested with linear mixed models: group, time (months postpartum) and the interaction group $\times$ time were included as fixed effects, and heifer as a random effect. For multiple comparisons, we applied the Bonferroni post hoc test using an $\alpha$-correction. Results are shown as mean \pm SEM. Significant differences were declared at $P<0.05$ and trends at $0.05<P<0.1$. The sample size in trial 2 (9 to 10 animals per group) was too low to allow for sufficient power to correctly reject (or not) the null hypothesis.

\section{RESULTS}

\section{Trial 1: Growth Performance and Feed Intake}

The ADG and BW during the first 15 wk of life (trial 1) are shown in Figure 1 and in Table 2, respectively. Birth weight was not different among treatment groups. ADG was greatest in the ad libitum-fed calves $(P<0.05)$ in $\mathrm{P} 1$ and exceeded the gains of the MR-res group by a factor of 1.44 (WM-ad lib) and 1.58 (MRad lib), respectively. In P2, ADG tended to be greater $(P<0.1)$ in MR-res compared with MR-ad lib calves, whereas ADG in MR-res versus WM-ad lib calves and MR-ad lib versus WM-ad lib calves were not different. Recorded BW was highest in MR-ad lib calves $(P<$ $0.05)$ at the end of $\mathrm{P} 1$ and was higher in WM-ad lib calves than in MR-res calves $(P<0.05)$. At the end of P2 and P3, BW was not different among groups and ADG during P3 was not different (Figure 1 and Table 2). Sex differences in BW and ADG were limited to P3 (Table 2 and Figure 1); feed intake was not different between sexes.

Feed intakes from the different phases of trial 1 (amounts and ME) are presented in Table 3. The in- 
Table 2. Development of BW ( $\mathrm{kg} \pm \mathrm{SEM})$ during the first $110 \mathrm{~d}$ of life (trial 1)

\begin{tabular}{lccc}
\hline & \multicolumn{3}{c}{ Feeding $^{1}$} \\
\cline { 2 - 4 } BW & MR-res $(\mathrm{n}=20)$ & MR-ad lib $(\mathrm{n}=17)$ & WM-ad lib $(\mathrm{n}=20)$ \\
\hline Birth weight & $41.9 \pm 0.8$ & $41.8 \pm 1.4$ & $42.3 \pm 1.3$ \\
BW at the end of phase 1 (d 27) & $56.4^{\mathrm{a}} \pm 1.0$ & $65.4^{\mathrm{b}} \pm 1.9$ & $63.9^{\mathrm{b}} \pm 1.8$ \\
BW at the end of phase 2 (d 70) & $95.8 \pm 1.9$ & $98.4 \pm 2.9$ & $99.0 \pm 2.1$ \\
BW at the end of phase 3 (d 110) & $131.6 \pm 2.6$ & $131.3 \pm 4.2$ & $133.7 \pm 3.1$ \\
\hline a,b Different lowercase letters indicate differences between groups $(P<0.05)$. & \\
${ }^{1}$ Feeding groups (differential feeding was limited to d 4 to 27 of age): MR-res $=$ milk replacer restrictive, MR-ad \\
lib = milk replacer ad libitum, WM-ad lib = whole milk ad libitum. \\
${ }^{2}$ Sex differences were limited to phase 3: males, 137.6 kg \pm 2.3 ; females, $127.0 \mathrm{~kg} \pm 2.6 ; P=0.004$.
\end{tabular}

take of colostrum with the first meal (MR-res 2,334 $\mathrm{g} \pm 211 ; \mathrm{WM}$-ad lib 2,349 $\mathrm{g} \pm 237 ;$ MR-ad lib 2,245 $\mathrm{g} \pm 211)$ and the amount of colostrum consumed per day from d 0 to 1 of age (P0) was not different among groups (Table 3). In phase 1 (P1, d 2 to 27$)$, MR and WM intake were approximately 1.4-fold greater (about $3 \mathrm{~kg}$ more of liquid feed) in both ad libitum-fed groups than in the MR-res group (Table 3). During P1, the calves ate only very low and highly variable amounts of concentrate $(0.07-0.25 \mathrm{~kg} /$ calf $/ \mathrm{d})$ that did not differ among groups. In phase 2 (P2, d 28 to 69 ), after differential feeding was completed and all animals were fed according to the MR-res regimen, the amount of liquid feed was reduced by about $60 \%$ of the previous daily allowance for the ad libitum-fed groups; in the MR-ad

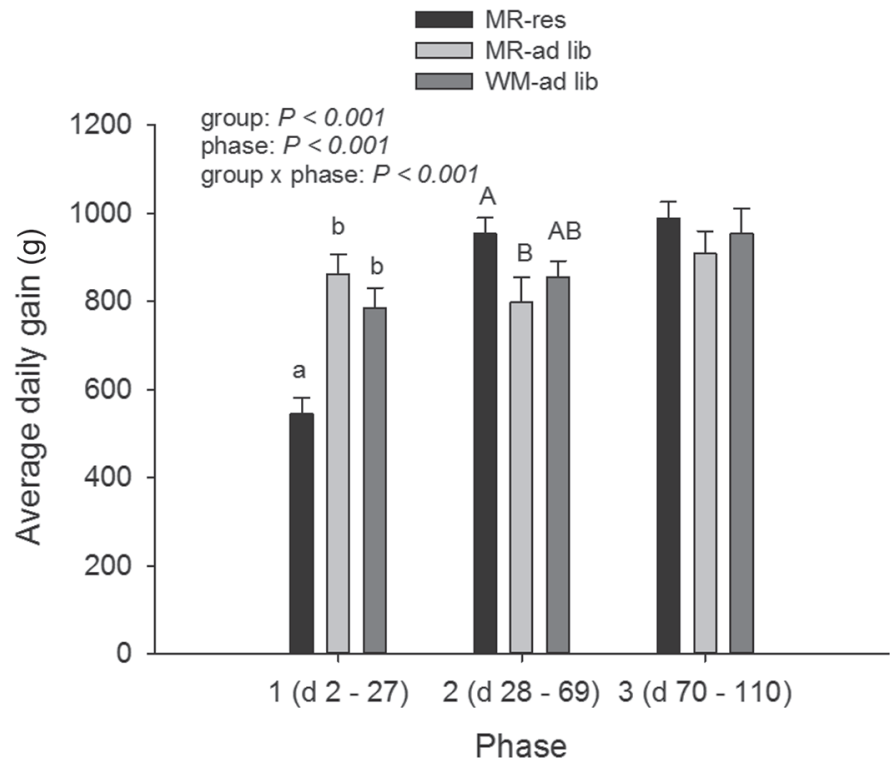

Figure 1. Development of ADG (means \pm SEM) from birth until wk 15 of life (trial 1). Different letters indicate differences among groups within the respective phase (lowercase letters, $P<0.001$; capital letters, $P<0.1)$. Sex differences were limited to phase 3: $P<0.05$; males: $1,028 \mathrm{~g} \pm 36$; females: $876 \mathrm{~g} \pm 44$. Feeding groups: MR-res $=$ milk replacer restrictive, $\mathrm{MR}$-ad lib $=$ milk replacer ad libitum, WMad lib $=$ whole milk ad libitum. lib group, the amount of MR powder was reduced to $52 \%$ on average when switching to the MR-res regimen. The intake of concentrate by MR-ad lib calves tended to be less $(P<0.1)$ than by WM-ad lib animals; no differences in concentrate intake were detectable between MR-res and MR-ad lib or between MR-res and WMad lib, respectively (Table 3). The daily energy intake $(\mathrm{ME})$ via milk in $\mathrm{P} 0$ was the same for all groups. In contrast, the ME intake via milk in $\mathrm{P} 1$ was different $(P$ $<0.05$ ) among all groups, with the greatest intakes in the WM-ad lib group, exceeding those in MR-ad lib and MR-res by factors of 1.8 and 2.1, respectively. In P2, the ME intake via milk was not different among groups. The ME intake via concentrate in P1 was not different among groups. In the subsequent phase of equal feeding (P2), the ME intake from concentrate was greatest in the WM-ad lib group, with no difference compared to the MR-res group, but a trend for greater intake in the MR-res group than in the MR-ad lib group $(P<0.10)$. Total ME intake via milk and concentrate was greater $(P<0.05)$ in the WM-ad lib group than in the MR-ad lib and MR-res groups in P1, but was not different among groups in P2 (Table 3).

Feeding frequency patterns (i.e., the daily number of visits in the automatic feeders) are shown in Figure 2. During P1, the number of total visits was greater in the MR-res group, whereby the proportion of unrewarded visits (when the calves entered the feeder but feed was not dispensed) amounted to $70 \%$ of total visits. The average number of rewarded visits across all groups was 6.9/d during P1. Thereafter, when all groups were on the MR-res diet (P2), the total visits from calves of both ad lib groups were more than twice as frequent than in P1 and reached $70 \%$ unrewarded visits (similar to the MR-res group during P1 and P2).

\section{Trial 2: Performance During the First Lactation}

As mentioned earlier, the number of female calves from trial 1 that were enrolled in trial 2 was limited, so this part of the study was actually underpowered. 


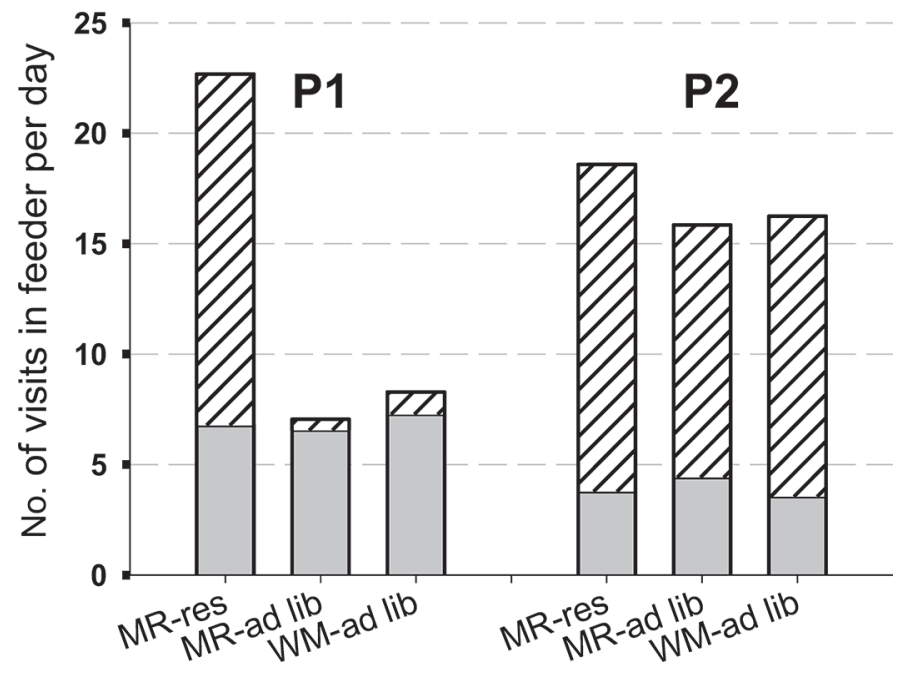

Figure 2. Daily visits at the automatic feeders by dairy calves fed at different intensities during the first 4 wk of life (trial 1). P1 = phase of differential feeding from d 2 to 27 of life; P2 $=$ phase when all calves were fed according to the restrictive regimen (d 28-69 of life). Feeding groups: $\mathrm{MR}$-res $=$ milk replacer restrictive, $\mathrm{MR}$-ad lib $=$ milk replacer ad libitum, WM-ad lib = whole milk ad libitum. Solid bars $=$ mean number of rewarded visits when feed was obtained; hatched bars = mean number of unrewarded visits during which no feed was obtained due to the restrictions. Feeders were set to maximum allowances of 5 L (ad libitum) and $2 \mathrm{~L}$ (restricted) per visit; liquid feed was dispensed only if calves had left at least $0.5 \mathrm{~L}$ (ad libitum) or $1 \mathrm{~L}$ (restricted) of their daily allowance. Phase and the interaction of group $\times$ phase were significant $(P<0.001)$
Milk yield, DMI, energy balance, and back fat thickness recorded during 10 mo of the first lactation are depicted in Figure 3. In Figure 4, BW during lactation is shown. None of these variables was different among the animal groups originating from the different feeding regimens during calfhood. In addition, BCS was not different among groups (data not shown). When considering ECM yields based on monthly milk recordings, the lactation curves of the heifers from the different groups separated only during the last $2 \mathrm{mo}$; the $P$-value for group was 0.168 . When considering 305 -d milk yield (Table 4), the WM-ad lib heifers produced numerically more milk $(+765 \mathrm{~kg}$ or $+9 \%)$ than heifers reared on the MR-res regimen. The milk yield in the first lactation of the MR-ad lib animals was $612 \mathrm{~kg}(+7 \%)$ above that of the MR-res heifers, but all comparisons were below the level of significance $(P=0.969)$. Average milk fat percentage, protein percentage, fat and protein yields, and feed efficiency ( $\mathrm{kg}$ of ECM/kg of DMI; Table 4) did not differ among treatment groups. Age at first calving was numerically lower in WM-ad lib heifers than in the other groups, but the threshold of significance was not reached (Table 4$)$.

\section{Trials 1 and 2: Economic Considerations}

Economic estimates based on feed costs for rearing until first calving and performance in the first lactation

Table 3. Milk replacer (MR), whole milk (WM), concentrate, and energy intake (ME) in the different phases of trial 1 (mean \pm SEM)

\begin{tabular}{|c|c|c|c|}
\hline \multirow[b]{2}{*}{ Intake } & \multicolumn{3}{|c|}{ Feeding $^{1}$} \\
\hline & MR-res $(\mathrm{n}=20)$ & MR-ad lib $(\mathrm{n}=17)$ & WM-ad lib $(n=20)$ \\
\hline \multicolumn{4}{|c|}{ MR or WM ( $\mathrm{g}$ of liquid intake) } \\
\hline Phase $0(\mathrm{~d} 0-1)$ & $4,015 \pm 243$ & $4,827 \pm 348$ & $4,736 \pm 410$ \\
\hline Phase 1 (d 2-27) & $6,385^{\mathrm{b}} \pm 39$ & $9,249^{\mathrm{a}} \pm 150$ & $9,470^{\mathrm{a}} \pm 137$ \\
\hline Phase 2 (d 28-69) & $5,724 \pm 50$ & $5,833 \pm 53$ & $5,723 \pm 50$ \\
\hline \multicolumn{4}{|l|}{ Concentrate (g) } \\
\hline Phase 0 & - & - & - \\
\hline Phase 1 (d 2-27) & $254 \pm 21$ & $101 \pm 12$ & $68 \pm 9$ \\
\hline Phase 2 (d 28-69) & $1,234^{\mathrm{AB}} \pm 24$ & $1,054^{\mathrm{B}} \pm 25$ & $1,258^{\mathrm{A}} \pm 24$ \\
\hline \multicolumn{4}{|c|}{ ME intake $(\mathrm{MJ} / \mathrm{d})$ via milk } \\
\hline Phase $0(\mathrm{~d} 0-1)$ & $12.5 \pm 0.76$ & $15.0 \pm 1.08$ & $14.4 \pm 1.29$ \\
\hline Phase 1 (d 2-27) & $12.3^{\mathrm{c}} \pm 0.09$ & $21.1^{\mathrm{b}} \pm 0.34$ & $25.7^{\mathrm{a}} \pm 0.37$ \\
\hline Phase 2 (d 28-69) & $10.7 \pm 0.09$ & $10.9 \pm 0.10$ & $10.7 \pm 0.09$ \\
\hline \multicolumn{4}{|c|}{ ME intake $(\mathrm{MJ} / \mathrm{d})$ via concentrate } \\
\hline Phase 0 & - & - & - \\
\hline Phase 1 (d 2-27) & $1.04 \pm 0.11$ & $0.32 \pm 0.05$ & $0.23 \pm 0.04$ \\
\hline Phase 2 (d 28-69) & $12.6^{\mathrm{A}} \pm 0.25$ & $10.8^{\mathrm{B}, \mathrm{b}} \pm 0.25$ & $12.8^{\mathrm{a}} \pm 0.25$ \\
\hline \multicolumn{4}{|c|}{ Total ME intake $(\mathrm{MJ} / \mathrm{d})$} \\
\hline Phase 0 & - & - & - \\
\hline Phase 1 (d 2-27) & $13.0^{\mathrm{c}} \pm 0.14$ & $21.5^{\mathrm{b}} \pm 0.39$ & $26.2^{\mathrm{a}} \pm 0.43$ \\
\hline Phase 2 (d 28-69) & $23.3 \pm 0.21$ & $21.7 \pm 0.20$ & $23.5 \pm 0.21$ \\
\hline
\end{tabular}

${ }^{\mathrm{a}-\mathrm{c}}$ Different lowercase letters indicate differences between groups $(P<0.05)$.

${ }^{\mathrm{A}, \mathrm{B}}$ Different uppercase letters indicate trends $(P<0.10)$.

${ }^{1}$ Feeding groups: MR-res $=$ milk replacer restrictive, $\mathrm{MR}$-ad lib $=$ milk replacer ad libitum, WM-ad lib $=$ whole milk ad libitum. 

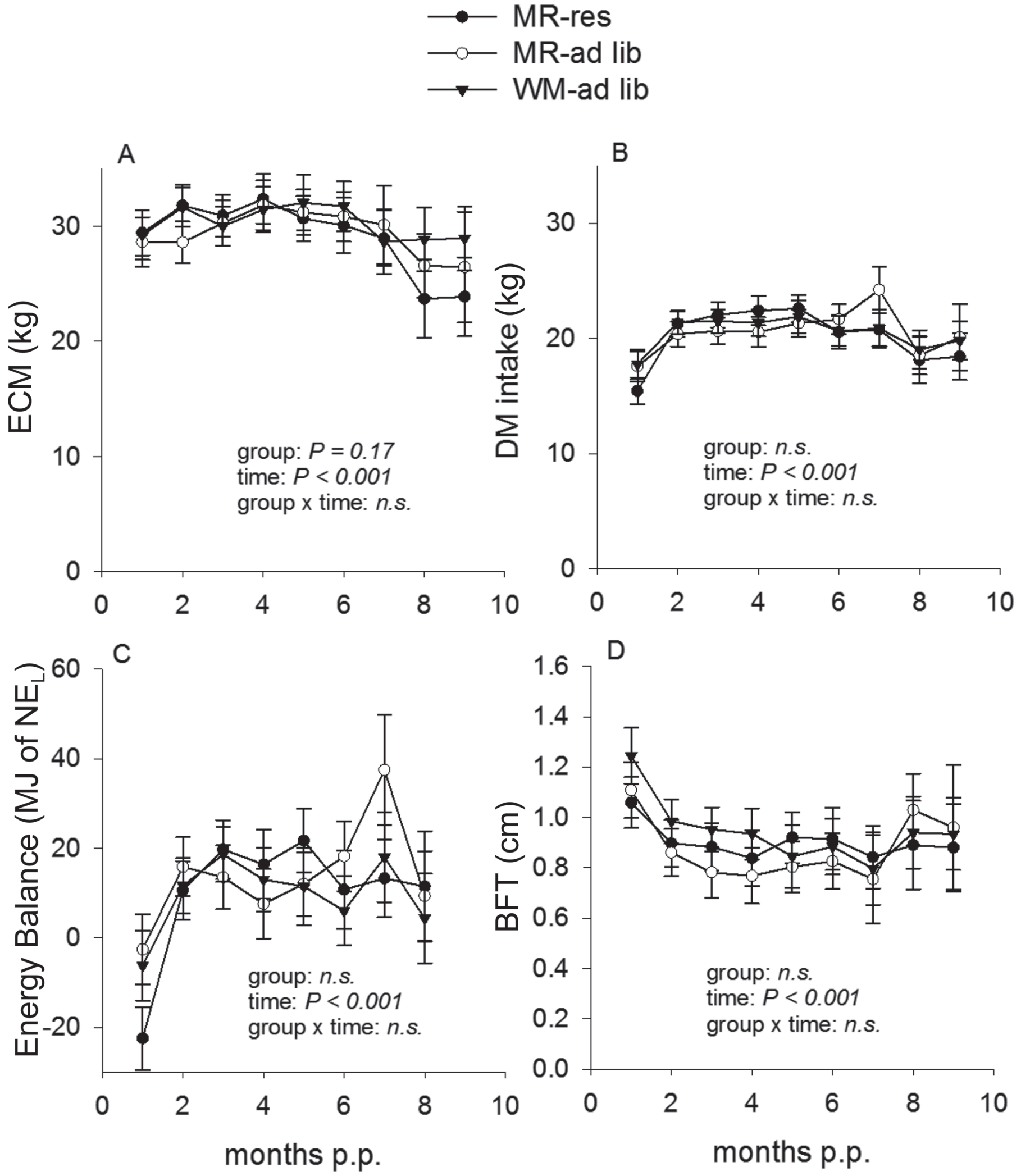

Figure 3. Development of (A) ECM, (B) DMI, (C) energy balance, and (D) back fat thickness (BFT) in the first 10 mo postpartum of the first lactation (mean \pm SEM; trial 2). Feeding groups: MR-res $=$ milk replacer restrictive, MR-ad lib $=$ milk replacer ad libitum, WM-ad lib $=$ whole milk ad libitum. 
Table 4. First-lactation performance (mean \pm SEM) in heifers (trial 2) reared at different feeding intensities over the first 4 wk of life

\begin{tabular}{lcccc}
\hline & \multicolumn{3}{c}{ Feeding $^{1}$} & \\
\cline { 2 - 4 } First-lactation performance & MR-res (n=10) & MR-ad lib (n=9) & WM-ad lib (n=9) & P-value: Group \\
\hline Age at first calving (d) & $775 \pm 18.0$ & $773 \pm 16.8$ & $745 \pm 15.2$ & 0.969 \\
305-d milk yield (kg) & $8,452 \pm 402$ & $9,064 \pm 432$ & $9,217 \pm 475$ & 0.919 \\
305-d fat yield (kg) & $329 \pm 15.2$ & $358 \pm 13.4$ & $347 \pm 15.8$ & 0.925 \\
305-d protein yield (kg) & $279 \pm 14.4$ & $300 \pm 12.8$ & $300 \pm 17.5$ & 0.646 \\
Fat (\%) & $3.85 \pm 0.07$ & $3.77 \pm 0.05$ & $3.83 \pm 0.07$ & 0.171 \\
Protein (\%) & $3.32 \pm 0.04$ & $3.22 \pm 0.04$ & $3.22 \pm 0.05$ & 0.693 \\
ECM/DMI (kg/kg) & $1.50 \pm 0.05$ & $1.46 \pm 0.04$ & $1.50 \pm 0.03$ & 0.722 \\
\hline
\end{tabular}

${ }^{1}$ Feeding groups: MR-res $=$ milk replacer restrictive, $\mathrm{MR}$-ad lib $=$ milk replacer ad libitum, $\mathrm{WM}$-ad lib $=$ whole milk ad libitum.

are presented in Table 5. We considered means instead of individual intake, because records of individual intake were limited to the liquid feeding period; for the remaining time, we used an average value for rearing heifers in our region under comparable conditions. Variations in the recorded variables and statistical comparisons have been described in the paragraphs above. On average, the WM-ad lib regimen created the greatest feed costs during the liquid feeding phase: €56 and €28 more than for MR-res and MR-ad lib feeding, respectively. When relating feed costs during liquid feeding to $\mathrm{kg}$ of

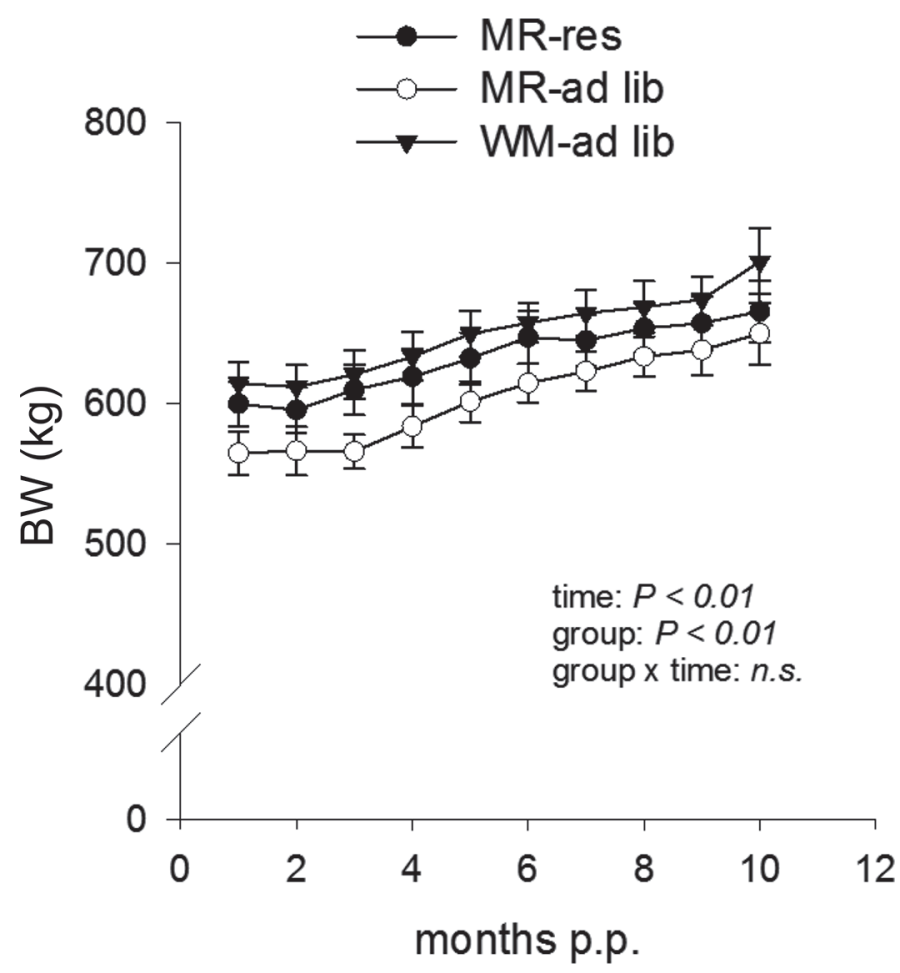

Figure 4. Development of BW (mean \pm SEM) in heifers over the first $10 \mathrm{mo}$ of the first lactation (trial 2). Feeding groups: MR-res $=$ milk replacer restrictive, $\mathrm{MR}$-ad lib $=$ milk replacer ad libitum, WMad lib = whole milk ad libitum.
BW gain during this time, the ranking was similar: the WM-ad lib feeding was 1.17- and 1.35-fold more costly than the MR-ad lib and MR-res feeding, respectively. Considering the entire period of rearing until first calving, the proportion of costs for liquid feeding phase as part of the total feed costs for rearing were 17.9, 15.1, and $12.7 \%$ for the WM-ad lib, MR-ad lib, and MR-res groups, respectively. Taking the returns from milk sale into consideration, which were (numerically) greater in the WM-ad lib group than in the MR-ad lib and MRres groups, WM-ad lib feeding yielded $€ 310$ and $€ 71$ more returns over feed costs than the MR-res or the MR-ad lib regimens. When expressed per $\mathrm{kg}$ of milk, the difference would amount to $€ 0.008$ and $€ 0.002$ (i.e., the returns over rearing feed costs in WM-ad lib calves would be 2.5 and $0.6 \%$ above those of heifers reared with MR-res or MR-ad lib).

\section{DISCUSSION}

\section{Performance During Calfhood}

Several studies have demonstrated that heifer calves fed WM or MR ad libitum increased their daily nutrient intake and had greater growth rates during the nursery period (Shamay et al., 2005; Moallem et al., 2010; Kiezebrink et al., 2015). In the current study, ad libitum feeding of WM or MR over the first $4 \mathrm{wk}$ of life increased BW only during this period, without any sustained difference at 15 wk of life. Similar results have been observed by Morrison et al. (2012) and Kiezebrink et al. (2015), where BW differences had disappeared by 84 to 126 wk of age and by 16 wk of age, respectively. In our study, the calves were all fed MR restrictively after the first 4 weeks of life. The increased growth rates from the previous ad libitum MR or WM feeding could be maintained only if the energy intake via concentrate had been increased accordingly and the development of the gastrointestinal tract was adequate to digest the concentrate. It is well documented that starter intake 
Table 5. Estimates of feed costs $(€)$ for rearing heifers fed differently during the first 4 wk of life in relation to the milk returns during their first lactation

\begin{tabular}{|c|c|c|c|}
\hline \multirow[b]{2}{*}{ Item } & \multicolumn{3}{|c|}{ Feeding $^{1}$} \\
\hline & $\begin{array}{c}\text { MR-res } \\
(\mathrm{n}=10)\end{array}$ & $\begin{array}{l}\text { MR-ad lib } \\
\quad(\mathrm{n}=9)\end{array}$ & $\begin{array}{c}\text { WM-ad lib } \\
\quad(\mathrm{n}=9)\end{array}$ \\
\hline Concentrate costs (d 4-70) & 21.4 & 17.6 & 20.7 \\
\hline Whole milk + milk replacer costs & 109.5 & 140.7 & 166.1 \\
\hline Total feed costs from d 1 to 70 & 130.9 & 158.3 & 186.8 \\
\hline Feed costs per $\mathrm{kg}$ of $\mathrm{BW}$ gain from $\mathrm{d} 1$ to 70 & 2.43 & 2.80 & 3.29 \\
\hline Total feed costs for heifers ${ }^{2}$ & 1,026 & 1,051 & 1,044 \\
\hline Milk returns from first lactation ${ }^{3}$ & 3,634 & 3,898 & 3,963 \\
\hline Milk returns over rearing feed costs & 2,608 & 2,847 & 2,918 \\
\hline Milk returns over rearing feed costs per $\mathrm{kg}$ of milk & 0.308 & 0.314 & 0.316 \\
\hline
\end{tabular}

and fermentation of starch in the rumen are responsible for rumen development (NRC, 2001), and ADG in calves between birth and 2 mo of age is positively related to starter intake (Heinrichs and Heinrichs, 2011; Bateman et al., 2012). Increased intake of liquid feed reportedly decreases concentrate intake (Khan et al., 2007a,b; Chapman et al., 2016), but contrasting results have also been obtained: when feeding calves ad libitum over $37 \mathrm{~d}$ (Jasper and Weary, 2002) and $21 \mathrm{~d}$ (Maccari et al., 2015) of life, concentrate intake after weaning did not decrease. In Maccari et al. (2015), calves fed ad libitum for $21 \mathrm{~d}$ had greater starter intake from wk 7 to 10 of life compared with restrictively fed calves. We were expecting MR-res calves to have superior concentrate intake, because they were encouraged by the limited supply of MR to start concentrate intake and adapt their gastrointestinal function to solid feed earlier than the ad libitum-fed calves. However, we did not observe group differences in concentrate intake during P1, probably because the amounts were low and highly variable. Concentrate intake starts only at about $14 \mathrm{~d}$ of age (Khan et al., 2011). During P2, the WM-ad lib calves had a higher concentrate intake, but only compared to the MR-ad lib group; the WM-ad lib and the MR-ad lib groups had similar concentrate intake to the MR-res group. Khan et al. (2007b) reported higher concentrate intake after weaning in calves fed intensively fed until d 25 of life. In that study, calves were stepped down from d 25 until d 49 to achieve a smooth transition from milk to solid feed. In contrast, the ad libitumfed calves in our study were turned to the restrictive MR regimen within $2 \mathrm{~d}$ but remained on liquid feed until weaning, starting at $\mathrm{d} 55$. The transition from a functional monogastric to a ruminant digestive system with the change from liquid to solid feed is one of the most dramatic gastrointestinal transformations in a ruminant's life (Steele et al., 2016), and it affects the animal's health (Hulbert and Moisá, 2016). The timing of this transition is a management decision, and intake of both concentrate and of forage (hay, silage, straw, pasture) is important for rumen development (Khan et al., 2016). However, taking the ME intakes from liquid and solid feed together in P2, the groups in our study were not different. We observed a trend for greater gains in the MR-res group than in the MR-ad lib group in P2, indicating that MR-res feeding and WM-ad lib feeding may have resulted in greater feed efficiencies. This trend for greater gains might also have resulted from comparison with the previous MR-ad lib feeding group; a dip in their growth curve might have occurred, whereas the MR-res were able to increase their growth rate. After weaning, when all calves had free access to a TMR for lactating cows (6.8 $\mathrm{MJ} \mathrm{NE}_{\mathrm{L}} / \mathrm{kg} \mathrm{DM}$ ), maintaining increased growth rates via increasing feed intake might have been possible, but was not observed during the $39 \mathrm{~d}$ phase following weaning. Chapman et al. (2016) showed that the greater ADG and BW in calves fed at a high level before weaning were not maintained, but reduced afterward. This finding might be attributable to constraints in the digestive capacity for the diet fed after weaning (Chapman et al., 2016). Khan et al. (2016) concluded in a recently published review that the provision of high-starch and low-fiber starter feeds may negatively affect rumen development, and that forage supplementation is beneficial for promoting gut development and rumination behavior in young calves. We could not quantify the intake of hay offered to calves from d 4 of life and can thus not address this aspect. It is certainly important for maintaining high growth rates after weaning that the diet allows 
for this in terms of amount, nutrient concentration, and digestibility.

Given the frequent feeder visits of the MR-res group during P1, and the high portion of unrewarded visits, it seems likely that this regimen left the animals unsatisfied and possibly frustrated by the unrewarded visits, which may in turn have been stressful. This pattern was continued in P2, and occurred accordingly in the ad libitum-fed animals when they were transferred to the MR-res regimen. As to whether this level of suspected stress might have metabolic consequences above nutrient intake remains unknown. However, although sustained effects seem improbable considering the ADG and BW after the liquid feeding phases, restrictive feeding implies reduced welfare (Khan et al., 2016).

Our findings that calves had equal growth rates after weaning were not in support of sustained programming of overall growth rate through feed intake or feed efficiency by feeding regimens during the first weeks of life. Nevertheless, alterations might have taken place at the level of individual organs, showing effects only in later life, or being too subtle to translate into growth performance. A greater feeding intensity $(1.2 \mathrm{~kg} / \mathrm{d}$ of MR) during the preweaning period has been demonstrated to improve nutrient intake, growth rates, and gastrointestinal development at weaning (Eckert et al., 2015). Geiger et al. (2016) showed in a recent report that higher growth rates over the first $8 \mathrm{wk}$ of life increased organ weights per $\mathrm{kg}$ of $\mathrm{BW}$ (e.g., liver and mammary gland).

\section{Performance During the First Lactation}

In trial 2, we followed the performance of the heifer calves from trial 1 until the end of their first lactation, although the sample size was too small to allow for sufficient power. In a meta-analysis of studies testing the effects of an enhanced supply of nutrients from WM or MR to dairy calves on milk yield in the first lactation, Soberon and Van Amburgh (2013) showed that the overall milk yield response was $435 \pm 117 \mathrm{~kg} /$ lactation $(P<0.001)$. The individual studies analyzed had not equivocally reported significant effects and were also mostly underpowered. However, when we used the equation developed from the meta-regression for the effect of ADG during preweaning on milk yield by Soberon and Van Amburgh (2013), the predicted increase in milk yield in our study amounted to $330 \mathrm{~kg}$ for both ad libitum-fed groups on average. The actual (numerical) increase we observed was an average of 688 $\mathrm{kg}$ for the 2 ad libitum-fed groups, more than double the calculated value. However, regardless of the absolute numbers, our study was in line with the general notion and our starting hypothesis that early intensive feeding with increased growth rates had beneficial effects on milk yield in later life, although our findings were not significant.

Based on the lack of differences among groups and the marginal numerical difference in $305 \mathrm{~d}$ milk yield between the MR-ad lib and WM-ad lib groups (+153 $\mathrm{kg}$ or $1.12 \%$ more), the source of nutrients in early life seems unimportant for milk yield in later life. This finding is in line with earlier studies as summarized by Soberon and Van Amburgh (2013). Our hypothesis that WM-fed calves would perform better than MR-fed ones in later life was not substantiated, but the limitations in terms of power must be kept in mind. However, when considering the data on concentrate intake and ME intake after the differential feeding, WM-fed calves had some advantage over MR-fed ones, at least during calfhood.

\section{Economics}

Total feed costs over the preweaning period were greater in both groups fed ad libitum, similar to results presented by Brown et al. (2005) and Raeth-Knight et al. (2009). Total costs per calf were higher in the WM-ad lib group, and also when related to a $\mathrm{kg}$ gain and compared to the MR-fed groups. The reason for the lesser total feed costs for rearing until first calving in the WM-ad lib group was due to the numerically lower age at first calving for WM-ad lib calves. The returns from milk were greatest in the WM-ad lib group. When related to total rearing feed costs, returns over feed costs seemed able to compensate for the additional expenses during the preweaning phase. These results support the positive effect of higher investment during the nursery period without any negative effect on economics in heifers over the first lactation.

\section{CONCLUSIONS}

Ad libitum intake of whole milk or milk replacer during the first 4 wk of life increased ADG and BW until d 28, but not thereafter. Restrictive feeding of MR stimulated concentrate intake to the same extent as ad libitum feeding of whole milk. Accelerated BW gain over the first $28 \mathrm{~d}$ of life did not impair milk yield, milk ingredients, DMI, energy balance, BW, body condition, or back fat thickness in the first lactation. The numerical but not statistically significant increase in milk yield was in line with previous findings and supports the notion that intensified feeding strategies may improve lactation performance. Further research is 
needed to identify an optimal transition from liquid to solid feed, with a focus on the development of a healthy rumen, gut, well-adapted microbiome and all bodily functions, allowing for a long and productive life span.

\section{ACKNOWLEDGMENTS}

We thank the technical staff of the Educational and Research Center for Animal Husbandry, Hofgut Neumuehle, Muenchweiler a.d. Alsenz, Germany. This research was partly conducted by members of the Center of Integrated Dairy Research (CIDRe), University of Bonn (Bonn, Germany).

\section{REFERENCES}

Baldwin, R. L. V., K. R. McLeod, J. L. Klotz, and R. N. Heitmann. 2004. Rumen development, intestinal growth and hepatic metabolism in the pre- and postweaning ruminant. J. Dairy Sci. 87:E55E65.

Bartol, F. F., A. A. Wiley, and C. A. Bagnell. 2008. Epigenetic programming of porcine endometrial function and the lactocrine hypothesis. Reprod. Domest. Anim. 43:273-279.

Bartol, F. F., A. A. Wiley, D. J. Miller, A. J. Silva, K. E. Roberts, M. L. Davolt, J. C. Chen, A. L. Frankshun, M. E. Camp, K. M. Rahman, J. L. Vallet, and C. A. Bagnell. 2013. Lactation biology symposium: Lactocrine signaling and developmental programming. J. Anim. Sci. 91:696-705.

Bateman, H. G. II, T. M. Hill, J. M. Aldrich, R. L. Schlotterbeck, and J. L. Firkins. 2012. Meta analysis of the impact of initial serum protein concentration and empirical prediction model for growth of neonatal Holstein calves through eight weeks of age. J. Dairy Sci. 95:363-369.

Blättler, U., H. M. Hammon, C. Morel, C. Philipona, A. Rauprich, V. Rome, I. Le Huërou-Luron, P. Guilloteau, and J. W. Blum. 2001. Feeding colostrum, its composition and feeding duration variably modify proliferation and morphology of the intestine and digestive enzyme activities of neonatal calves. J. Nutr. 131:1256-1263.

Blum, J. W., and H. M. Hammon. 2000. [Bovine colostrum: More than just an immunoglobulin supplier]. Schweiz. Arch. Tierheilkd. 142:221-228. [In German]

Brown, E. G., M. J. Vandehaar, K. M. Daniels, J. S. Liesman, L. T. Chapin, J. W. Forrest, R. M. Akers, R. E. Pearson, and M. S. Nielsen. 2005. Effect of increasing energy and protein intake on mammary development in heifer calves. J. Dairy Sci. 88:595-603.

Burrin, D. G., T. A. Davis, S. Ebner, P. A. Schoknecht, M. L. Fiorotto, and P. J. Reeds. 1997. Colostrum enhances the nutritional stimulation of vital organ protein synthesis in neonatal pigs. J. Nutr. 127:1284-1289.

BZA-Rind. $2013 . \quad$ Rinderreport Rheinland-Pfalz. Betriebszweigauswertung der Milchviehberatungsringe. Accessed Dec. 20, 2016. http://www.dlr.rlp.de/internet/global/themen. nsf/d0e5087e9e1e8b79c1257abf0060c5df/F6211CB12459431AC1 257B6300245B23/\$FILE/Rinderreport\%202013\%20RLP.pdf. [In German]

Chapman, C. E., P. S. Erickson, J. D. Quigley, T. M. Hill, H. G. Bateman II, F. X. Suarez-Mena, and R. L. Schlotterbeck. 2016. Effect of milk replacer program on calf performance and digestion of nutrients with age of the dairy calf. J. Dairy Sci. 99:2740-2747. https://doi.org/10.3168/jds.2015-10372.

Donovan, S. M., and J. Odle. 1994. Growth factors in milk as mediators of infant development. Annu. Rev. Nutr. 14:147-167.

Eckert, E., H. E. Brown, K. E. Leslie, T. J. DeVries, and M. A. Steele. 2015. Weaning age affects growth, feed intake, gastrointestinal development, and behavior in Holstein calves fed an elevated plane of nutrition during the preweaning stage. J. Dairy Sci. 98:6315-6326.
Edmonson, A. J., I. J. Lean, L. D. Weaver, and T. Farver. 1989. A body condition scoring chart for Holstein dairy cows. J. Dairy Sci. $72: 68-78$

Geiger, A. J., C. L. Parsons, R. E. James, and R. M. Akers. 2016. Growth, intake, and health of Holstein heifer calves fed an enhanced preweaning diet with or without postweaning exogenous estrogen. J. Dairy Sci. 99:3995-4004. https://doi.org/10.3168/ jds.2015-10405.

GfE (German Society of Nutrition Physiology). 2001. Empfehlungen zur Energie- und Nährstoffversorgung der Milchkühe und Aufzuchtrinder. DLG-Verlag, Frankfurt/Main, Germany. [In German]

Heinrichs, A. J., and B. S. Heinrichs. 2011. A prospective study of calf factors affecting first lactation and lifetime milk production and age of cows when removed from the herd. J. Dairy Sci. 94:336-341.

Hulbert, L. E., and S. J. Moisá. 2016. Stress, immunity, and the management of calves. J. Dairy Sci. 99:3199-3216.

Jasper, J., and D. M. Weary. 2002. Effects of ad libitum milk intake on dairy calves. J. Dairy Sci. 85:3054-3058.

Jentsch, W., M. Derno, M. Klein, P. Junghans, and B. Löhrke. 2000. Research note: Is starch utilization for fat deposition in man different from that in animals? Arch. Tierernaehr. 53:395-398. https:// doi.org/10.1080/17450390009381960.

Kesser J., M. Korst, C. Koch, F.-J. Romberg, J. Rehage, U. Müller, M. Schmicke, K. Eder, H. M. Hammon, H. Sadri, and H. Sauerwein. 2017. Different milk feeding intensities during the first 4 weeks of rearing dairy calves: Part 2: Effects on the metabolic and endocrine status during calfhood and around the first lactation. J. Dairy Sci. 100:3109-3125. https://doi.org/10.3168/jds.2016-11595.

Khan, M. A., A. Bach, D. M. Weary, and M. A. G. von Keyserlingk. 2016. Invited review: Transitioning from milk to solid feed in dairy heifers. J. Dairy Sci. 99:885-902.

Khan, M. A., H. J. Lee, W. S. Lee, H. S. Kim, K. S. Ki, T. Y. Hur, G. H. Suh, S. J. Kang, and Y. J. Choi. 2007a. Structural growth, rumen development, and metabolic and immune responses of Holstein male calves fed milk through step-down and conventional methods. J. Dairy Sci. 90:3376-3387.

Khan, M. A., H. J. Lee, W. S. Lee, H. S. Kim, S. B. Kim, K. S. Ki, J. K. Ha, H. G. Lee, and Y. J. Choi. 2007b. Pre- and postweaning performance of Holstein female calves fed milk through step-down and conventional methods. J. Dairy Sci. 90:876-885.

Khan, M. A., D. M. Weary, D. M. Veira, and M. A. von Keyserlingk. 2012. Postweaning performance of heifers fed starter with and without hay during the milk-feeding period. J. Dairy Sci. 95:3970-3976.

Khan, M. A., D. M. Weary, and M. A. von Keyserlingk. 2011. Invited review: Effects of milk ration on solid feed intake, weaning, and performance in dairy heifers. J. Dairy Sci. 94:1071-1081.

Kiezebrink, D. J., A. M. Edwards, T. C. Wright, J. P. Cant, and V. R. Osborne. 2015. Effect of enhanced whole-milk feeding in calves on subsequent first-lactation performance. J. Dairy Sci. 98:349-356.

Maccari, P., S. Wiedemann, H. J. Kunz, M. Piechotta, P. Sanftleben, and M. Kaske. 2015. Effects of two different rearing protocols for Holstein bull calves in the first 3 weeks of life on health status, metabolism and subsequent performance. J. Anim. Physiol. Anim. Nutr. (Berl.) 99:737-746.

Margerison, J. K., A. D. J. Robarts, and G. W. Reynolds. 2013. The effect of increasing the nutrient and amino acid concentration of milk diets on dairy heifer individual feed intake, growth, development, and lactation performance. J. Dairy Sci. 96:6539-6549. https://doi.org/10.3168/jds.2012-6489.

Moallem, U., D. Werner, H. Lehrer, M. Zachut, L. Livshitz, S. Yakoby, and A. Shamay. 2010. Long-term effects of ad libitum whole milk prior to weaning and prepubertal protein supplementation on skeletal growth rate and first-lactation milk production. J. Dairy Sci. 93:2639-2650.

Morrison, S. J., H. C. F. Wicks, A. F. Carson, R. J. Fallon, H. Twigge, D. J. Kilpatrick, and S. Watson. 2012. The effect of calf nutrition on the performance dairy herd replacements. Animal 6:909-919.

NRC. 2001. Nutrient Requirements of Dairy Cattle. 7th rev. ed. Natl. Acad. Press, Washington, DC. 
Quigley, J. D., 3rd, L. A. Caldwell, G. D. Sinks, and R. N. Heitmann 1991. Changes in blood glucose, nonesterified fatty acids, and ketones in response to weaning and feed intake in young calves. J. Dairy Sci. 74:250-257.

Raeth-Knight, M., H. Chester-Jones, S. Hayes, J. Linn, R. Larson, D. Ziegler, B. Ziegler, and N. Broadwater. 2009. Impact of conventional or intensive milk replacer programs on Holstein heifer performance through six months of age and during first lactation. J. Dairy Sci. 92:799-809.

Rauprich, A. B., H. M. Hammon, and J. W. Blum. 2000a. Effects of feeding colostrum and a formula with nutrient contents as colostrum on metabolic and endocrine traits in neonatal calves. Biol. Neonate 78:53-64.

Rauprich, A. B., H. M. Hammon, and J. W. Blum. 2000b. Influence of feeding different amounts of first colostrum on metabolic, endocrine, and health status and on growth performance in neonatal calves. J. Anim. Sci. 78:896-908.

Robelin, J., and Y. Chilliard. 1989. Short-term and long-term effects of early nutritional deprivation on adipose tissue growth and metabolism in calves. J. Dairy Sci. 72:505-513.

Schröder, U. J., and R. Staufenbiel. 2006. Invited review: Methods to determine body fat reserves in the dairy cow with special regard to ultrasonographic measurement of backfat thickness. J. Dairy Sci. $89: 1-14$
Shamay, A., D. Werner, U. Moallem, H. Barash, and I. Bruckental. 2005. Effect of nursing management and skeletal size at weaning on puberty, skeletal growth rate, and milk production during first lactation of dairy heifers. J. Dairy Sci. 88:1460-1469.

Soberon, F., E. Raffrenato, R. W. Everett, and M. E. Van Amburgh. 2012. Preweaning milk replacer intake and effects on long-term productivity of dairy calves. J. Dairy Sci. 95:783-793.

Soberon, F., and M. E. Van Amburgh. 2013. Lactation biology symposium: The effect of nutrient intake from milk or milk replacer of preweaned dairy calves on lactation milk yield as adults: A metaanalysis of current data. J. Anim. Sci. 91:706-712.

Steele, M. A., G. P. Penner, F. Chaucheyras-Durand, and L. Luo Guan. 2016. Development and physiology of the rumen and the lower gut: Targets for improving gut health. J. Dairy Sci. 99:4955-4966.

Suarez-Mena, F. X., T. M. Hill, A. J. Heinrichs, H. G. Bateman 2nd, J. M. Aldrich, and R. L. Schlotterbeck. 2011. Effects of including corn distillers dried grains with solubles in dairy calf feeds. J. Dairy Sci. 94:3037-3044.

VDLUFA (Verband Deutscher Landwirtschaftlicher Untersuchungsund Forschungsanstalten). 2007. Handbuch der Landwirtschaftlichen Versuchs- und Untersuchungsmethodik (VDLUFA-Methodenbuch), Bd. III. Die chemische Untersuchung von Futtermitteln, 3. Aufl. inkl. 1-7. Ergänzungslieferung. VDLUFA-Verlag, Darmstadt, Germany. [In German] 